\title{
BMJ Open Role of community pharmacists in the use of antipsychotics for behavioural and psychological symptoms of dementia (BPSD): a qualitative study
}

\author{
Ian D Maidment, ${ }^{1}$ Lydia Aston, ${ }^{2}$ Andrea Hilton, ${ }^{3}$ Naveed Iqbal, ${ }^{4}$ Anne Child, ${ }^{5}$ \\ Rachel Shaw ${ }^{2}$
}

To cite: Maidment ID, Aston L, Hilton A, et al. Role of community pharmacists in the use of antipsychotics for behavioural and psychological symptoms of dementia (BPSD):

a qualitative study. BMJ Open 2016;6: 010278

doi:10.1136/bmjopen-2015010278

- Prepublication history and additional material is available. To view please visit the journal (http://dx.doi.org/ 10.1136/bmjopen-2015010278)

Received 16 October 2015 Revised 20 November 2015 Accepted 6 January 2016

CrossMark

For numbered affiliations see end of article.

Correspondence to Dr lan D Maidment; i. maidment@aston.ac.uk

\section{ABSTRACT}

Objective: This study aimed to use qualitative methodology to understand the current role of community pharmacists in limiting the use of antipsychotics prescribed inappropriately for behavioural and psychological symptoms of dementia.

Design: A qualitative study employing focus groups was conducted. Data were analysed using thematic analysis.

Setting: 3 different geographical locations in the England.

Participants: Community pharmacists $(\mathrm{n}=22)$.

Results: The focus groups identified an array of factors and constraints, which affect the ability of community pharmacists to contribute to initiatives to limit the use of antipsychotics. 3 key themes were revealed: (1) politics and the medical hierarchy, which created communication barriers; (2) how resources and remit impact the effectiveness of community pharmacy; and (3) understanding the nature of the treatment of dementia.

Conclusions: Our findings suggest that an improvement in communication between community pharmacists and healthcare professionals, especially general practitioners (GPs) must occur in order for community pharmacists to assist in limiting the use of antipsychotics in people with dementia. Additionally, extra training in working with people with dementia is required. Thus, an intervention which involves appropriately trained pharmacists working in collaboration with GPs and other caregivers is required. Overall, within the current environment, community pharmacists question the extent to which they can contribute in helping to reduce the prescription of antipsychotics.

\section{BACKGROUND}

Dementia has an estimated global prevalence of over 35 million people. ${ }^{1}$ Dementia affects over 800000 in the UK. ${ }^{2}$ People with

\section{Strengths and limitations of this study}

- As far as we are aware, this is the only published study that has investigated the views of community pharmacists on whether they can contribute to the initiative to limit the use of antipsychotics.

- The results require triangulation with general practitioners, and people with dementia and their carers.

- Participants were recruited from three different geographical locations in the UK and data saturation was achieved.

dementia, like other older people, may be prescribed complex medication regimens, increasing the risk of drug interactions and adverse events. ${ }^{34}$ Of particular concern is the potentially inappropriate prescribing of antipsychotic medication in people with dementia, which has been associated with 1800 deaths annually due to an increased risk of stroke and pneumonia. ${ }^{5}$ While a recent national audit identified that antipsychotic prescriptions for people with dementia reduced by $52 \%$ between 2008 and 2011, this audit did not collect data on harm and relied on the accuracy of the dementia registers. ${ }^{6}$

Limiting the use of antipsychotics in dementia is a key public health objective and a key recommendation of the Banerjee report. $^{5}$ The National Dementia Strategy highlighted the role of pharmacist-led medication review, which could be implemented by community pharmacists. $^{5}$ Furthermore, both the Royal Pharmaceutical Society tool kit and guidance from Alzheimer's Society have identified a potential role for community pharmacists. $^{7} 8$ While the National Dementia Strategy only applies to England, 
there is a need to limit the use of antipsychotics across the $\mathrm{UK}^{78}$

While there is a significant literature on pharmacists providing clinical services in general, there is little on services specifically in dementia care. ${ }^{9-21}$ One crosssectional survey explored the knowledge, experience and attitudes of community pharmacists on pain experienced by people with dementia and its management. ${ }^{12}$ Another study found that a pharmacy-led programme could support withdrawing antipsychotics in people with dementia; however, this clinical service was delivered by a specialist dementia care pharmacist. ${ }^{20}$ There is also a current cluster randomised controlled trial in the Netherlands which aims to improve psychotropic usage in nursing home residents with dementia. ${ }^{9}$ The intervention is a structured multidisciplinary medication review involving pharmacists, physicians and nurses, and education delivered within the nursing home. ${ }^{9}$

There may be significant barriers to community pharmacists delivering such a role, ${ }^{914} 21$ and outcomes from pharmacy-led interventions have been variable. ${ }^{11} 1314$ Community pharmacists do not usually have full access to the patients' clinical histories and the Summary Care Record may not contain enough information. ${ }^{14} 22$ Commonly, the prescribing decision rests with the general practitioner (GP) which means community pharmacists can only make clinical recommendations, and indeed in some cases may not even know if their suggestions were acted on. ${ }^{14}$ Furthermore, GPs may not believe that community pharmacists can add clinical value to chronic disease management. ${ }^{23}$ This study used qualitative methodology to examine the current role of community pharmacists with respect to the use antipsychotics in behavioural and psychological symptoms of dementia (BPSD).

\section{AIMS AND OBJECTIVES}

\section{Aim}

To understand the current role of community pharmacists in limiting the use of antipsychotics prescribed inappropriately for BPSD.

\section{Objectives}

To understand the opinions and experience of community pharmacists, focusing on their knowledge and opinions of the national initiative.

To identify barriers and facilitators to community pharmacists developing a role in this clinical area.

\section{METHODS}

Design

An exploratory study was conducted which utilised a semistructured schedule to guide discussions in focus groups. Three focus groups were facilitated by LA, a health psychologist in training. They were audiorecorded, transcribed verbatim and analysed using thematic analysis.

\section{Participants}

Three focus groups were held in three different geographical locations in England: the North East (NE), West Midlands (WM) and South East (SE; precise areas have been kept anonymous). This ensured a wide geographical representation and the possibility for a wide range of experiences.

The criteria for inclusion in the study were that all participants worked or had worked, whether full or part time, as a community pharmacist.

\section{Sampling and recruitment}

Participants were recruited through local pharmaceutical networks. The study was advertised on the relevant, geographically specific Local Pharmaceutical Committee (LPC) websites, which explained what taking part in the research involved the criteria the individual had to meet in order to do so, as well as the date the focus group would occur. Purposive sampling was originally employed. This developed into a snowball sample as data were gathered, and contacts were asked to suggest other community pharmacists who might be willing to take part in this study. The contact details of LA were provided on the advert, and potential participants were at liberty to contact via email to express interest. An email with an information sheet, consent form and expression of interest form would be attached and emailed back to these interested individuals, and after consenting, LA gave the venue details and time of the focus group to the participants. Written consent was obtained from all participants prior to data collection.

\section{Data collection}

Ethics approval was granted by the appropriate University Research Ethics Committee in June 2013 and the study was conducted between September and November 2013. Each focus group was co-facilitated by an experienced pharmacist to support LA with any specialist pharmacy terminology. For the focus group to take place, between 4 and 10 participants were required. The interview schedule consisted of open-ended questions to avoid leading participants' responses (see online supplementary appendix 1). Prompts were included in the schedule and were employed if required.

\section{Data analysis}

The focus groups were recorded and the recordings transcribed (using a transcription service). These transcripts were analysed using thematic analysis (coded by LA). Thematic analysis was used because it is a flexible method which is able to provide a detailed and complex account of qualitative data, and is widely used in healthcare research. ${ }^{24}$ IDM and RS also independently reviewed the transcripts and the coding by LA. Any disagreements over interpretation of the data were discussed between LA, IDM and RS until consensus was reached. Deviant case analysis was also performed in order to reduce any bias. Three key concepts were 
elicited from the data with subthemes within these three themes.

\section{RESULTS}

Twenty-two participants were recruited (14 females and 8 males): NE: 6 ( 4 females, 2 males), WM: 5 (1 females, 4 males), SE: 11 (9 females, 2 males; for further demographic information see online supplementary appendix 2). It was not possible to state the number of pharmacists approached and the number who declined due to the method used to recruit participants.

When discussing the role community pharmacists have in reducing the prescription of antipsychotics in dementia, the focus groups revealed an undercurrent of concern as to whether this was manageable within the constraints of their role, as well as an array of factors which would have to be considered and altered. Three themes were revealed: (1) politics and the medical hierarchy; (2) how resources and remit impact the effectiveness of community pharmacy; and (3) understanding the nature of the treatment of dementia.

Theme 1: politics and the medical hierarchy

Similar discussion between groups was elicited, which concentrated on the relationship of community pharmacists with GPs. This was expressed in a way that suggested feelings of inferiority towards GPs, which in turn created a barrier in communication. This was perceived to be perpetuated by the attitude of GPs, who the participants felt, were unwilling to listen to their perspective:

Even if you say it in the right manner, you still haven't got any real authority. So he can tell you whatever he wants. (WM2)

Community pharmacists believed that they needed to exert considerable effort to improve their working relationship, but perceived a lack of recognition of their job status:

Tact and diplomacy are required but, as you say, you are quite likely to get a message back saying, "You are neither a consultant nor a prescriber, so toe the line. (WM5)

This idea that, because community pharmacists are not GPs or consultants, community pharmacists believed that others thought their opinions lacked validity, which affected their interactions with GPs. The above extract also suggests that even if GPs are polite with community pharmacists, they may still be interpreted as patronising, demonstrated through the GPs' questioning, which undermined both the expertise of community pharmacists and the legitimacy of their concern for the patient's welfare.

A level of self-doubt and, indeed, fear was portrayed when the participants considered their own remit as professionals in relation to communication with GPs:

And I wanted to ask you, just to expand this and I don't mean this disrespectfully at all...but would you also be fearful about your skill set if the GP said to you, OK, let's withdraw it. Tell me how to do it. (SE3)

Yes. Absolutely. Yes. (SE-general consensus)

This signified a general lack of self-efficacy within the profession and had a direct impact on the self-efficacy of the community pharmacists.

This lack of communication between community pharmacists and GPs was further exacerbated when participants explained how they had contacted GPs and in some cases, consultants, only to never receive a reply. Even when the community pharmacists had successfully contacted GPs, GPs had not altered their practice based on the concerns presented to them:

I've never succeeded in getting a GP to say, “OK, we'll scrub that". (WM5)

All of the above paints a compelling picture of community pharmacists not having their voices heard, or the voice they once had being silenced by negative experiences. This is further impaired by the lack of resources that community pharmacists have access to.

Theme 2: how resources and remit impact the effectiveness of community pharmacy

There was an overall consensus across the groups that community pharmacists were under-resourced and without adequate power within the existing parameters of their work. This included no direct access to patients' records, which they believed was vital for any role in limiting the use of antipsychotics:

We don't have access to notes in terms of their records. (SE11)

This limited their effectiveness in this area and demonstrates that community pharmacists do not yet feel suitably trained in the specialised area of treatment of BPSD:

We, as pharmacists, well currently we haven't been trained unless you are a specialist, in behavioural changes. We have no equipment on that at all...I would feel at the moment totally out of my depth. (SE10)

Participants reported feeling significant uncertainty about the remit of their profession with regard to this initiative:

It's always difficult to know what is appropriate and inappropriate in psychotic medicine. (NE2)

However, community pharmacists already manage busy schedules and the feasibility of implementing increased scope needs to be investigated:

One of the major obstacles is time...you haven't got the time to put that into practice. (WM5) 
The idea of introducing another responsibility into this role raises challenges, not least with respect to community pharmacists' professional identity, competency and stretched resources. Furthermore, in the absence of an incentive for community pharmacists to take on additional work, it is unlikely that this role will develop:

If you were reimbursed more appropriately for patients who take a lot more time to be dealt with. (NE4)

More fundamentally, awareness of the current objective to reduce the use of antipsychotics in people with dementia needs to be raised among community pharmacists:

I wasn't aware of any specific initiative. (WM5)

Well, I know there was a call to action some time ago, several years ago I think, wasn't it, I think. (SE6)

Theme 3: anomalies and uncertainty: understanding the nature of the treatment of dementia

The community pharmacists also questioned whether or not it was appropriate to query the prescribing of antipsychotics in people with dementia. They believed that there was a need to balance the safety of the patient and others versus the side effects of antipsychotics.

This patient is going crazy, flying off the walls, it's in the patient's best interest to sort her out because...you have to balance the risk and benefit. (WM3)

This again portrays the sense of uncertainty about what is best for the patient and the ambiguity experienced by community pharmacists partly due to the lack of access to information. Furthermore, if GPs cannot be contacted, the community pharmacist must either dispense the drugs or not dispense them until they have managed to reach the GP and discussed the prescription with the GP; this may be difficult if the community pharmacist does not know the patient, or has not spoken to the patient's family. In addition, questions arose surrounding the issue of consent and who has permission to give it when confronted with dementia treatment issues:

So if it's a third party, unless they are caught in the ethical gap, so like, you need to discuss it with the person themselves. So if the person is in a position where they can't come in to your pharmacy and you can't go there to discuss it with them. (SE3)

With this uncertainty combined with the pressures identified in all the themes, the community pharmacists appeared to neglect dementia care:

Dementia gets put on the too difficult to do pile. (SE3)

\section{DISCUSSION}

All extracts presented paint a complex picture of the heterogeneous nature of dementia and the multifaceted issues related to its treatment. We observed a negative cycle within community pharmacists' accounts which seemed to stem from a lack of professional confidence, which developed a sense of inferiority, which was exacerbated by a lack of training and challenging symbiotic relationships with GPs. ${ }^{25}$ This problem is further aggravated by not having access to patient records, lack of financial incentives and current workload issues. The Department of Health and the Royal Pharmaceutical Society highlight the role that community pharmacists could play in helping reduce the prescription of antipsychotics. ${ }^{5} 7$ However, the extent to which community pharmacists feel they can contribute to this initiative is limited.

People with dementia may be a greater risk of medication-related adverse events due to the impact of cognitive impairment. ${ }^{26}{ }^{27}$ Like other research, on the role of community pharmacists in general, we found that isolation, poor integration into the healthcare team, being viewed as 'shopkeepers' re-enforcing a sense of inferiority and lack of access to records inhibit community pharmacists from developing a clinical role. ${ }^{1428-33}$ It is unclear from this investigation whether or not the attitude of GPs is a primary cause, a contributing factor or simply a consequence of community pharmacists' low self-efficacy.

While, as far as we are aware, this is the first published study that has investigated the involvement of community pharmacists in supporting the appropriate use of medication to treat BPSD; other research has found barriers in other specific dementia syndromes, such as pain, suggesting that dementia care is an area that community pharmacists generally find particularly challenging. ${ }^{12}$ Our research also confirms some of the issues identified by the Royal Pharmaceutical Society. ${ }^{7}$ The pharmacist may not be able to rely on the person with dementia as an historian; thus, there is greater reliance on the clinical record. The public may be particularly reluctant to trust pharmacists to deliver services that are perceived as risky, such as the treatment of BPSD. ${ }^{30}$ Finally, we found that accessible training to improve the skills in the pharmacy workforce, sufficient time and a collaborative multidisciplinary approach are required to develop the community pharmacist role in this area, echoing previous research. ${ }^{1417313435}$

\section{Limitations of the study}

Qualitative methods often rely on smaller sample sizes to allow for participant accounts to be analysed in sufficient detail for the results to be meaningful. The participants in this study were a mix of ages and experiences (see online supplementary appendix 2 for more information) recruited from three different geographical locations in the UK, which was to the study's benefit. While data saturation was achieved, the findings require confirmation. Another limitation to this study is the lack of 
triangulation of results from community pharmacists with GPs and people with dementia and their carers.

\section{Implications for practice}

This research suggests that current policy initiatives to develop a clinical role for community pharmacists in dementia care are likely to be unsuccessful. Perceptions of community pharmacy held by key stakeholders need to change in general. ${ }^{29} 3036 \mathrm{~A}$ more collaborative approach with access to clinical records is required. However, concerns have been expressed that community pharmacies may use the National Health Service (NHS) data for commercial reasons, ${ }^{37}$ and the general public may be reluctant to allow access to health records unless the need for this access is clearly explained. ${ }^{33}$ If community pharmacists and GPs could develop an effective working relationship, link with specialist services, via a collaborative medication review, this could limit the inappropriate use of psychotropics to treat BPSD. ${ }^{21}$ Joint training with GPs and pharmacists is one potential promising avenue; in addition to developing the clinical skills of community pharmacists, the training could be a stepping stone towards a more collaborative approach to medication optimisation. ${ }^{143138}$

\section{Future research}

Our results suggest that any effective intervention, to reduce the prescription of antipsychotics in people with dementia, is likely to require the input of specially trained pharmacists working collaboratively with GPs, community pharmacists, patients and carers. Furthermore, it would require expertise from Health Psychologists to ensure any proposed behaviour change at the systemic level has a sound basis in evidenced behavioural science. ${ }^{39}{ }^{40}$ Authors of this paper are conducting two research projects in this area. First, we have received funding from Pharmacy Research UK to study the role of community pharmacists in medication management in dementia. Second, we hold an National Institute for Health Research (NIHR) grant (RfPB reference number: PB-PG-0613-31071) to investigate the feasibility of trialling a combined pharmacy and health psychology informed intervention to limit the use of psychotropic medication to treat BPSD and to prepare care home staff to care effectively for people with dementia exhibiting challenging behaviour. ${ }^{41}$ The intervention plans to use a collaborative model with experts from secondary care supporting primary care. Research should also investigate methods to improve collaboration between community pharmacists and GPs, in general.

\section{CONCLUSION}

This qualitative study found that community pharmacists question the extent that they can contribute to national objectives to reduce the prescription of antipsychotics for people with dementia. The pharmacists interviewed believed that issues such as suboptimal teamwork between community pharmacists and GPs, a lack of full access to records and limited training need to be addressed. These barriers may have a greater impact in dementia care, and therefore the ability of community pharmacists to contribute to care in this environment may be especially limited. A more collaborative approach to care, which allowed community pharmacists access to clinical records, along with appropriate training could start to address some of the issues raised. However, until these issues are addressed, community pharmacists will lack the knowledge and information, and therefore the confidence required to develop any meaningful role in this aspect of dementia care.

\section{Author affiliations}

${ }^{1}$ School of Life and Health Sciences, Aston Research Centre for Healthy Ageing (ARCHA), Aston University, Birmingham, UK

${ }^{2}$ School of Life and Health Sciences, Aston University, Birmingham, UK

${ }^{3}$ Faculty of Health and Social Care, University of Hull, Hull, UK

${ }^{4}$ Department of Pharmacy, School of Life and Health Sciences, Aston

University, Birmingham, UK

${ }^{5}$ Avante Care, Faversham, Kent, UK

Acknowledgements The authors would like to thank the community pharmacists for their participation in this study and Sally Greensmith (FRPharmS, RPS Surrey lead) who co-facilitated the SE focus group.

Contributors The project was designed by IDM with support from all co-authors. The ethics application was developed by LA with support from IDM and RS. LA conducted the interviews with support from IDM and AH. All authors contributed to data analysis and critical revision of the paper; additionally every author approved the final version.

Funding This research received no specific grant from any funding agency in the public, commercial or not-for-profit sectors.

Competing interests None declared.

Ethics approval Aston University Research Ethics.

Provenance and peer review Not commissioned; externally peer reviewed.

Data sharing statement No additional data are available.

Open Access This is an Open Access article distributed in accordance with the Creative Commons Attribution Non Commercial (CC BY-NC 4.0) license, which permits others to distribute, remix, adapt, build upon this work noncommercially, and license their derivative works on different terms, provided the original work is properly cited and the use is non-commercial. See: http:// creativecommons.org/licenses/by-nc/4.0/

\section{REFERENCES}

1. Alzheimer's Disease International 2013. World Alzheimer's report 2013 Journey of Caring: an analysis of long-term care for dementia. http://www.alz.co.uk/research/WorldAlzheimerReport2013.pdf (accessed 4 Aug 2015).

2. Alzheimer's Research UK. Dementia statistics. 2014. http://www. alzheimersresearchuk.org/dementia-statistics/?

gclid=COeXpKXM-b8CFcsJwwodJVsARQ (accessed 29 Sep 2015).

3. Schubert CC, Boustani M, Callahan CM, et al. Comorbidity profile of dementia patients in primary care: are they sicker. J Am Geriatric Soc 2006;54:104-9.

4. Poland F, Mapes S, Pinnock H, et al. Perspectives of carers on medication management in dementia: lessons from collaboratively developing a research proposal. BMC Res Notes 2014;7:463.

5. Department of Health. The use of antipsychotic medication for people with dementia: time for action living well with dementia: a National Dementia Strategy. London: Stationary Office, 2009. http://www.rcpsych.ac.uk/pdf/Antipsychotic\%20Bannerjee\% 20Report.pdf (accessed 29 Sep 2015).

6. Health and Social Care Information Centre (HSCIC). National Dementia and Anti-psychotic Prescribing Audit. http://www.ic.nhs.uk/ dementiaaudit (accessed 31 Jul 2015). 
7. Royal Pharmaceutical Society, Dementia Action Alliance, NHS Institute for Innovation and Improvement. The right prescription: a call to action reducing the inappropriate use of antipsychotic drugs for people with dementia. Royal Pharmaceutical Society, Dementia Action Alliance, NHS Institute for Innovation and Improvement, 2014. http://www.rpharms.com/support-pdfs/the-right-prescription.pdf (accessed on 31 Jul 2015).

8. Alzheimer's Society 2011. Optimising treatment and care for people with behavioural and psychological symptoms of dementia. A best practice guide for health and social care professionals. http://www. alzheimers.org.uk/site/scripts/download_info.php?fileID=1133 (accessed 29 Sep 2015).

9. Smeets $\mathrm{CH}$, Smalbrugge $\mathrm{M}$, Gerritsen $\mathrm{DL}$, et al. Improving psychotropic drug prescription in nursing home patients with dementia: design of a cluster randomized controlled trial. BMC Psychiatry 2013;13:280.

10. Jokanovic N, Tan ECK, van den Bosch D, et al. Clinical medication review in Australia: a systematic review. Res Social Adm Pharm 2015. [Epub ahead of print]. doi: 10.1016/j.sapharm.2015.06.007

11. Hohl CM, Wickham ME, Sobolev B, et al. The effect of early in-hospital medication review on health outcomes: a systematic review. Br J Clin Pharmacol 2015;80:51-61.

12. Barry HE, Parsons $C$, Passmore AP, et al. Community pharmacists and people with dementia: a cross-sectional survey exploring experiences, attitudes, and knowledge of pain and its management. Int J Geriatr Psychiatry 2013;10:1077-85.

13. Holland R, Lenaghan E, Harvey I, et al. Does home based medication review keep older people out of hospital? The HOMER randomised controlled trial. BMJ 2005;330:293.

14. RESPECT TEAM. Effectiveness of shared pharmaceutical care for elderly patients: RESPECT trial findings. Br J Gen Pract 2010;60: e10-19.

15. Holland R, Desborough J, Goodyer L, et al. Does pharmacist-led medication review help to reduce hospital admissions and deaths in older people? A systematic review and meta-analysis. Br J Clin Pharmacol 2008;65:303-16.

16. Zermansky AG, Petty DR, Raynor DK, et al. Randomised controlled trial of clinical medication review by a pharmacist of elderly patients receiving repeat prescriptions in general practice. $B M J$ 2001;323:1340-3.

17. Patterson SM, Hughes CM, Crealey G, et al. An evaluation of an adopted U.S. model of pharmaceutical care to improve psychoactive prescribing for nursing home residents in Northern Ireland (Fleetwood Northern Ireland Study). J Am Geriatr Soc 2010;58:44-53.

18. Spinewine A, Schmader KE, Barber N, et al. Appropriate prescribing in elderly people: how well can it be measured and optimised? Lancet 2007:370:173-84.

19. MEDMAN Team. The MEDMAN study: a randomized controlled trial of community pharmacy-led medicines management for patients with coronary heart disease. Fam Pract 2007;24: 189-200.

20. Child A, Clarke A, Fox C, et al. A pharmacy led program to review anti-psychotic prescribing for people with dementia. BMC Psychiatry 2012;12:155

21. Bryant LJM, Coster G, Gamble GD, et al. The General PractitionerPharmacist Collaboration (GPPC) study: a randomised controlled trial of clinical medication reviews in community pharmacy. Int $J$ Pharm Pract 2011;19:94-105.

22. Salter C. Compliance and concordance during domiciliary medication review involving pharmacists and older people. Sociol Health IIIn 2010;32:21-36.
23. Rieck AM. Exploring the nature of power distance on general practitioner and community pharmacist relations in a chronic disease management context. J Interprof Care 2014;28:440-6.

24. Braun V, Clarke V. Using thematic analysis in psychology. Qual Res Psychol 2006;3:77-101. http://eprints.uwe.ac.uk/11735/2/thematic analysis_revised_-_final.pdf (accessed 12 Nov 2015).

25. Morton $\mathrm{K}$, Pattison $\mathrm{H}$, Langley $\mathrm{C}$, et al. A qualitative study of English community pharmacists' experiences of providing lifestyle advice to patients with cardiovascular disease. Res Social Adm Pharm 2015;11:e17-29.

26. Maidment ID. Medication-related adverse events in older people with dementia; causes and possible solutions [PhD thesis]. Aston University, 2013.

27. Maidment ID, Haw C, Stubbs J, et al. Medication errors in older people with mental health problems: a review. Int $J$ Geriatr Psychiatry 2008;23:564-73.

28. Hughes CM, McCann S. Perceived interprofessional barriers between community pharmacists and general practitioners: a qualitative assessment. Br J Gen Pract 2003;53:600-6.

29. Gidman W, Cowley J. A qualitative exploration of opinions on the community pharmacists' role amongst the general public in Scotland. Int J Pharm Pract 2013;21:288-96.

30. Gidman W, Ward P, McGregor L. Understanding public trust in services provided by community pharmacists relative to those provided by general practitioners: a qualitative study. BMJ Open 2012;2:e000939.

31. West R, Isom M. Management of patients with hypertension: genera practice and community pharmacy working together. $\mathrm{Br} J$ Gen Pract 2014:64:477-8.

32. Trueman P, Taylor DG, Lowson K, et al. Evaluation of the scale, causes and costs of waste medicines. University of York and The School of Pharmacy, 2010.

33. Review of pharmacist access to electronic care records under way (10th July 2008) The Pharmaceutical Journal. http://www. pharmaceutical-journal.com/news-and-analysis/news/ review-of-pharmacist-access-to-electronic-care-records-under-way/ 10016416.article (accessed 29 Sep 2015)

34. Silcock J, Petty D. Pharmacist-led medication review: comment on Holland et al. Br J Clin Pharmacol 2008;66:575-6.

35. Seston E, Hassell K. British pharmacists' work-life balance-is it a problem? Int J Pharm Pract 2014;22:135-45.

36. Bissell P, Blenkinsopp A, Short D, et al. Patients' experiences of a community pharmacy-led medicines management service. Health Soc Care Community 2008;16:363-9.

37. Daily Telegraph. Boots, Tesco and Superdrug to get access to NHS medical records. 2015. http://www.telegraph.co.uk/news/health/ 11790711/Boots-Tesco-and-Superdrug-to-getaccess-to-NHS-medical-records.html (accessed 29 Sep 2015).

38. Campion P, Hilton A, Irving G, on behalf of the RESPECT Team Shared prescribing? A focus group study with community pharmacists. Prim Health Care Res Dev 2007;8:308-14.

39. French SD, Green SE, O'Connor DA, et al. Developing theory-informed behaviour change interventions to implement evidence into practice: a systematic approach using the Theoretical Domains Framework. Implement Sci 2012;7:38.

40. Michie S, Richardson M, Johnston M, et al. The behavior change technique taxonomy (v1) of 93 hierarchically clustered techniques: building an international consensus for the reporting of behavior change interventions. Ann Behav Med 2013;46:81-95.

41. NIHR-Research for Patient Benefit. Current, Completed and Closed project. 2015. (last updated February 2015). http://www.nihr.ac.uk/ research/research-for-patient-benefit.htm (accessed 9 Aug 2015). 